\title{
Effect of wetting-drying cycles on soil desiccation cracking behaviour
}

\author{
Chao-Sheng Tang ${ }^{1}$, Yu-Jun $\mathrm{Cui}^{2}$, Bin Shi ${ }^{1}$, Anh-Minh Tang ${ }^{2}, \mathrm{Ni} \mathrm{An}^{2}$ \\ ${ }^{1}$ School of Earth Sciences and Engineering, Nanjing University, 163Xianlin Avenue 210023, China \\ ${ }^{2}$ Ecole des Ponts ParisTech, UR Navier/CERMES, 6 et 8, avenue Blaise Pascal, Cité Descartes, Champs-sur-Marne, 77455 Marne-la- \\ Vallée CEDEX 2, France
}

\begin{abstract}
Better understanding the desiccation cracking process is essential in analysing drought effects on soil hydraulic and mechanical properties through consideration of the atmosphere-ground interaction. Laboratory tests were conducted to investigate the consequence of wetting-drying cycles on the initiation and propagation characteristics of desiccation cracks on soil surface. Initially saturated slurry specimens were prepared and subjected to five subsequent wetting-drying cycles. Image processing technique was employed to quantitatively analyze the morphology characteristics of crack patterns formed during each drying path. The results show that the desiccation cracking behaviour of soil is significantly affected by the wetting-drying cycles. Before the third wetting-drying cycle is reached, the surface crack ratio and the average crack width increases while the average clod area decreases with increasing the number of wetting-drying cycles. The number of intersections and crack segments per unit area reaches the peak values after the second wetting-drying cycle. After the third wetting-drying cycle is reached, the effect of increasing wetting-drying cycles on crack patterns is insignificant. Moreover, it is observed that the applied wettingdrying cycles are accompanied by a continual reconstruction of soil structure. The initial homogenous slurry structure is completely replaced with aggregated structure after the third cycles, and a significant increase in the inter-aggregate porosity can be observed.
\end{abstract}

\section{INTRODUCTION}

The formation of desiccation cracks on soil surface due to loss of water is a common phenomenon in nature. This behavior significantly affects the performance of soil in various geotechnical, geological and environmental applications. Generally, the presence of cracks in soil would increase the compressible and reduce the overall mechanical strength [1]. The hydraulic properties of soil are directly influenced by crack networks in soil [2]. Many researchers have found that the hydraulic conductivity of cracked soils is typically several orders of magnitude greater than that of uncracked soils [3]. Therefore, this issue is a major concern in designing and constructing low permeable structures as clay buffers and barriers for nuclear waste isolation, liners and covers for landfill, etc. So far, a number of laboratory experiments have been conducted to investigate the initiation and propagation of desiccation crack in soils [4, 5, 6-9]. In addition, some modeling and theory studies have also been conducted on this issue $[10,11]$. Nonetheless, the prediction of cracks initiation and the associated crack network propagation behaviour still faces several challenges.

Desiccation cracking is mainly due to water loss by evaporation which results in the generation of soil suction. Cracking is likely to occur if the surface tensile stress induced by increasing suction exceeded the bonding strength of soil grains [12]. However, the intrinsic mechanism of desiccation cracking is very complex. It is related to the physical, chemical, mechanical and hydraulic properties of soil, including clay proportion, mineral composition, compaction condition, initial water content, etc. [1,3]. Especially, climatic situations and surrounding geo-environments are known as important factors affecting soil desiccation cracking behaviour. Tang et al. (2007) and Tang et al. (2008) confirmed that the influences of environmental temperature and layer thickness on desiccation cracking behavior of clayey soil $[6,13]$. Rodríguez et al. (2007) analyzed the desiccation phenomena of a mining waste at different relative humidity conditions, and found that the time at onset of crack initiation decreases with decreasing relative humidity [14]. Moreover, the soil in field experiences diurnal or seasonal rainy and sunny climate changes, and undergoes periodical wetting-drying cycles. Several studies have been performed to investigate the effect of wetting and drying on soil physical properties [15]. However, there is a lack of data covering the desiccation cracking behavior of soil subjected to wetting-drying cycles.

The aim of this work is to determine how wettingdrying cycles affect the desiccation cracking behavior of soil. Initial homogenous slurry specimens were prepared

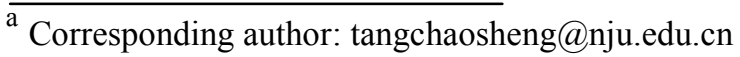


in laboratory and subjected to five wetting-drying cycles. The initiation and propagation of cracks on specimen surface were monitored during the cycles. The morphological characteristics of surface crack pattern were discribed and quantified based on image analysing method. Some interesting phenomena observed in the tests were discussed.

\section{Material and methods}

The used soil was taken from the Est of Paris. The physical properties are presented in Table 1. The soil was air-dried, crushed and sieved at $2 \mathrm{~mm}$. Saturated slurry specimens were prepared by mixing soil powder with distilled water at a water content of $170 \%$. The desired quantity of slurry was then poured into glass cups (117 $\mathrm{mm}$ in diameter). To remove entrapped air bubbles in the slurry, these cups were placed on a vibration device for few minutes. Finally, the cups containing prepared slurries were sealed with plastic membrane for 3 days. The final thickness of the settled slurry was about $10 \mathrm{~mm}$.

The prepared specimen was exposed in constant room temperature $\left(25 \pm 1{ }^{\circ} \mathrm{C}, 50 \pm 5 \%\right.$ of relative humidity, $R H)$ to be dried, until the residual water content was reached. Note that this is the first wetting-drying cycle. The subsequent wetting cycle was started with adding distilled water immediately into the glass cups. In this process, sufficient water was provided to ensure full saturation of the soil. Three days were allowed for the equilibration of soil and water.The glass cups were also sealed with plastic membrane to prevent evaporation of moisture. Then, the specimens were exposed in room temperature to be dried again. By repeating the above procedures, a total of five wetting-drying cycles were applied to the specimens.
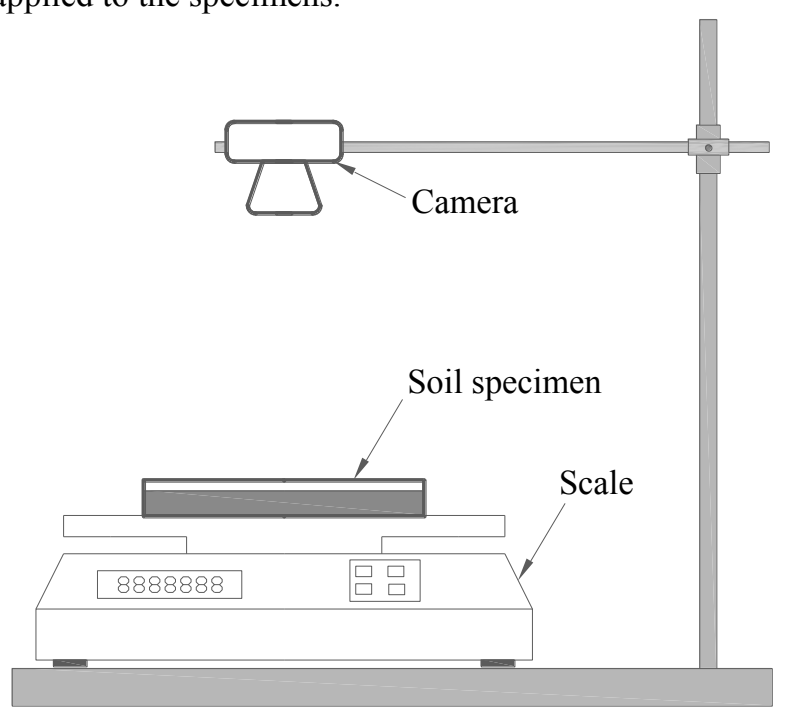

Figure 1. Schematic drawing of set-up.

During wetting and drying, a digital camera was mounted above the specimens to record the change of surface crack pattern, as the schematic drawing of the setup shown in Fig. 1. By applying computer image processing technique, the surface crack ratio $\left(R_{\mathrm{sc}}\right)$ which is the ratio of the surface area of cracks to the total surface area of specimen, was defined to quantify soil cracking extent during drying. In addition, some other parameters (i.e. the number of intersections, crack segments per unit area and the average width and clod area) that can be used to describe the geometric characteristics of crack pattern were also determined. The details and procedures of digital crack image processing were introduced by Tang et al. (2008) [6]. During the tests, the water evaporation and water content changes of specimens were monitored using a scale (Fig. 1).

Table 1. Physical properties of soil

\begin{tabular}{ll}
\hline Soil properties & Values \\
\hline Specific gravity & 2.79 \\
Liquid limit & $77 \%$ \\
Plastic limit & $40 \%$ \\
Plasticity index & 37 \\
USUC classification & $\mathrm{CH}$ \\
Clay $(<2 \mu \mathrm{m})$ & $79 \%$ \\
Clay composition & $\mathrm{Illite}$ and smectite \\
Specific surface area & $340 \mathrm{~m} / \mathrm{g}$ \\
\hline
\end{tabular}

\section{Results and Discussion}

\subsection{The first wetting-drying cycle}

Fig. 2 depicts the determined cracking curve $\left(R_{\mathrm{sc}}\right.$ versus $w)$ during the first drying cycle. It can be observed that the $R_{\mathrm{sc}}$ increases quickly with decreasing $w$ in the early stage of cracking. However, with further drying, the increment of $R_{\mathrm{sc}}$ decreases quickly once $w$ is lower than a specific value. From the cracking curve, the following two parameters can be identified: the cracking water content $\left(w_{\mathrm{c}}\right)$ which corresponds to the initiation of desiccation cracking, and the final critical water content $\left(w_{\mathrm{fc}}\right)$ which corresponds to the transition point where $R_{\mathrm{sc}}$ trends to stable value. It can be seen that cracking occurred at very high water content of about $38.1 \%$, that is closed to the plastic limit $(40 \%)$ of the used soil (Table $1)$. The final stabilized $R_{\mathrm{sc}}$ is about $15.8 \%$, means that there is $15.8 \%$ surface area was covered by cracks. As indicated by Tang et al. (2010a), the formed crack on soil surface is directly attributed to the shrinkage of pore volume [7]. When the water content reaches soil shrinkage limit, all particles are in contact, further water loss will not result in any more volume reduction. Accordingly, the cracks propagation also trends to end and reaches stabilization. They therefore concluded that the physical signification of $w_{\mathrm{fc}}$ determined from the cracking curve is identical with the shrinkage limit determined from shrinkage curve. For the tested soil, the shrinkage limit can be evaluated as about $11.3 \%$, based on the determined $w_{\mathrm{fc}}$ shown in Fig. 2. 


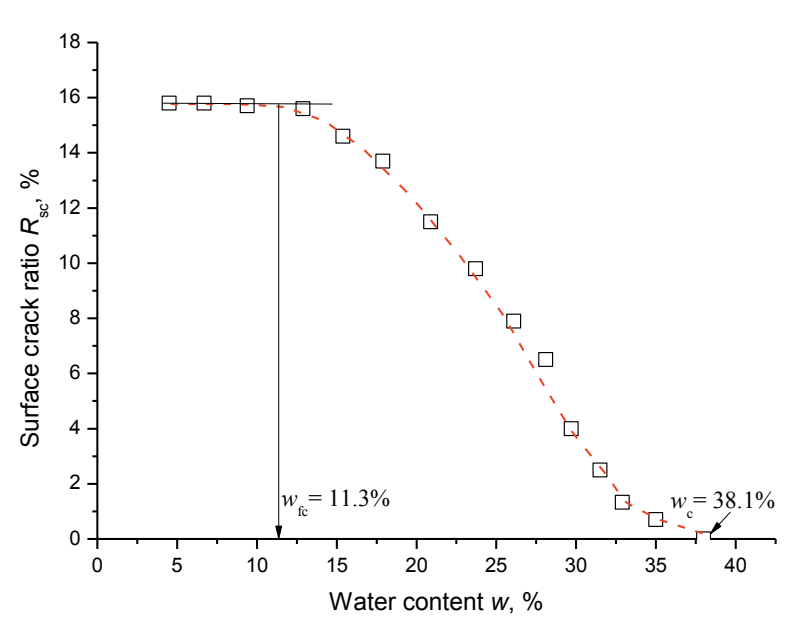

Figure 2. The cracking curve of specimen during the first drying cycles.

The initiation of desiccation crack on soil surface can be considered as tensile fracture of soil material. The $w_{\mathrm{c}}$ is therefore an very important critical parameters related to the mechanism of this phenomenon. However, even for a given soil, the $w_{\mathrm{c}}$ is not unique while conditioned by a lot of factors. Corte and Higashi (1960) and Nahlawi and Kodikara (2006) found that $w_{\mathrm{c}}$ generally increased as soil layer thickness increased [5, 12]. Rodríguez et al. (2007) confirmed that the $w_{\mathrm{c}}$ significantly depends on relative humidity [14]. Tang et al. (2010a) indicated that the $w_{\mathrm{c}}$ increases with increasing temperature [7]. According to the unsaturated soil mechanics theory, a given soil may initiate cracks at various critical suction levels due to the various $w_{\mathrm{c}}$. Because of the uncertainty of critical fracture conditions, it is currently difficult to construct an appropriate failure criterion to predict soil cracking behaviour. This is also why the precise mechanism of soil desiccation cracking is still not perfectly understood.

After the first drying cycle, a typical crack pattern is presented in Fig. 3. It can be seen that the specimen surface is split to several separate clods by the crack network. The shapes of clods and crack segments are relatively regular and smooth. Most of the clods are quadrangles and pentagons. A close observation of the crack pattern shows that most of the crack segments are perpendicular to each other.

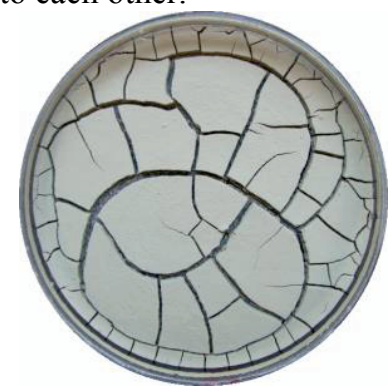

Figure 3. The crack pattern after the first wetting-drying cycle.
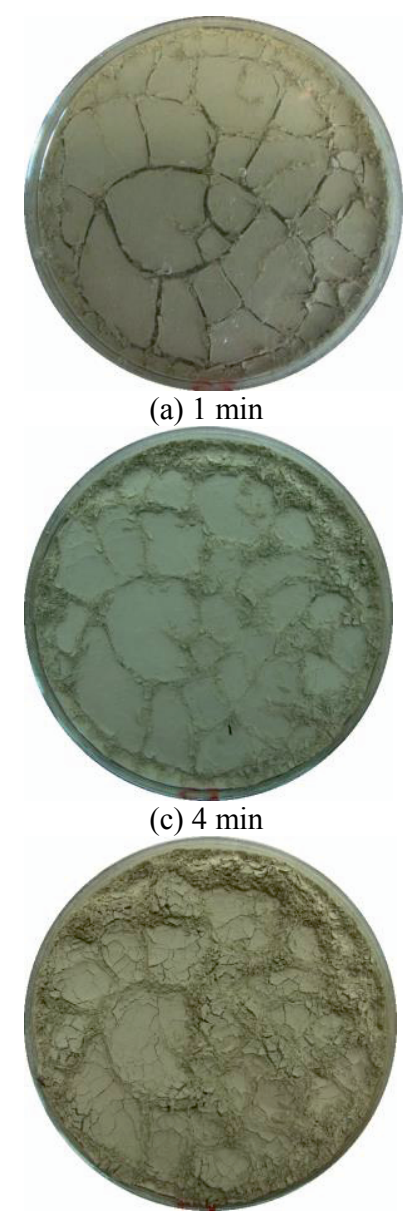

(d) $20 \mathrm{~min}$

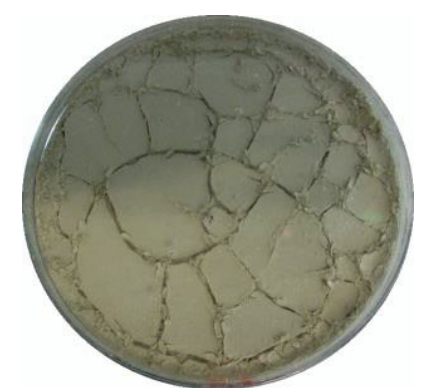

(b) 2 min

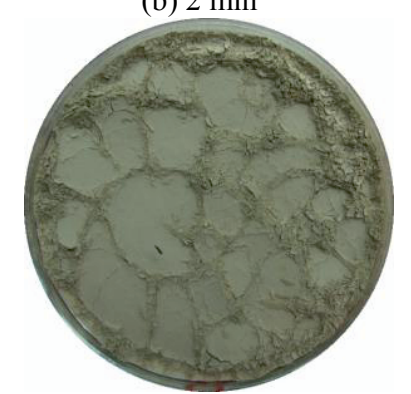

(d) $6 \mathrm{~min}$

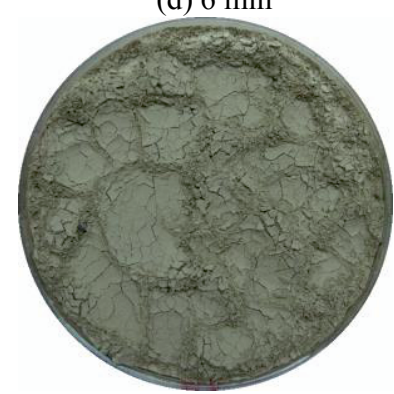

(e) $250 \mathrm{~min}$

Figure 4. The evolution of crack pattern during the second wetting path with elapsed time.

\subsection{The second wetting-drying cycle}

A series of 6 time-images are shown in Fig. 4 to describe the evolution of crack pattern during the second wetting path. After the water was put into the glass cup, immediate slaking of the clods was observed (Fig. 4 (a) and (b)). The clods broke down into several small aggregates. Some new microcracks appeared on specimen surface. This phenomenon can be attributed to the following factors:

i) The added water weakened particle bonding strength and softened soil structure.

ii) Internally generated forces such as differential swelling pressur resulted in the successive disintegration of the clods.

iii) Entrapment and pressurization of air bubbles inside the clods intensified the damage of soil structure. When water was put into the glass cup, it penetrated inside the clods driven by capillary forces. This rather brutal hydration process can lead to entrapment and pressurization of air bubbles (Fig. 5). Because capillary first develops in smallest pore spaces, the pore air is extruded and gradually gathers in macropores. On one hand, with successive gathering of pore air, the air bubble volume increases and leads to soil destruction. On the other hand, as hydration carries on, the pressure $P_{\mathrm{a}}$ inside 
the air bubbles increases due to the meniscus imbibition (Fig. 5). Once $P_{\mathrm{a}}$ exceeds the bonding strength of surrounding particles, it results in miniexplosions of soil structure, and thus leads to general damage. Some times, pressure equilibrium will be reached between the air bubbles and soil structure, these air bubbles will be more likely to be trapped and not escape to outside. This phenomenon was confirmed in present investigation, as the picture shown in Fig. 6. It is evident that the entrapped air bubble intensified the disaggregation of surrounding soil.

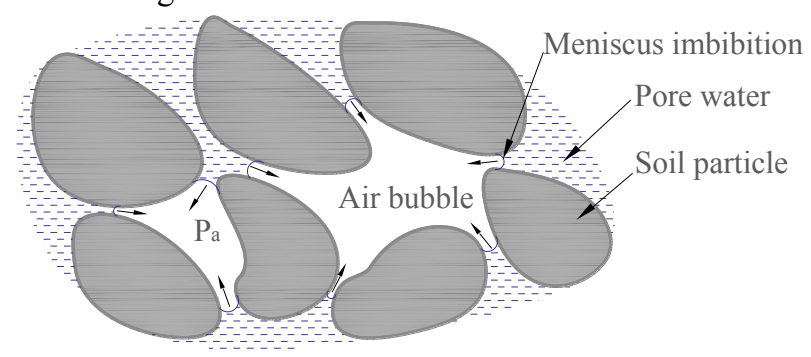

Figure 5. Meniscus imbibition during wetting.

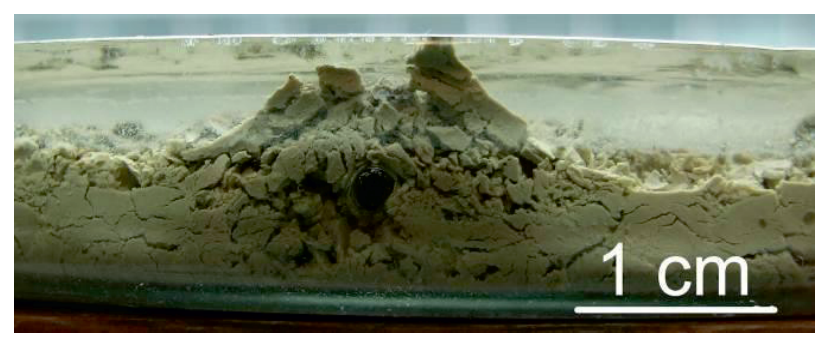

Figure 6. The entrapped air bubble inside the soil during wetting cycle

From Fig. 6 (a), it is interesting to find that the slaking or destruction of clods firstly occurred on the clods edges, especially on the corner positions of clods. This is because the hydration firstly occurred in these positions. With increasing wetting time, the original cracks became narrower and narrower due to clods collapse and swelling of soil particles, and were fully closed in 4 min (from Fig. 6 (a) to Fig. 6 (c)). But the new appeared microcracks became more and more with the elapsed wetting time (from Fig. 6 (d) to Fig. 6 (e)). It was found that the aggregates and the microscracks were always maintained during the whole wetting period, even after about 3 days later they still exist.

Sequences of wetting-drying cycles can lead to the rearrangement of soil particles and the modification of pore system. The reversibility of the soil structure during wetting-drying cycles is known to influence the hydraulic and mechanic behavior, including the volume shrinkage and swelling properties. Yong and Warkentin (1975) revealed that shrinkage during the first drying cycle caused irreversible fabric changes, particle bonds might be broken due to desiccation cracking [16]. These broken bonds may attract water and become weakest locations where are the preferential zones of cracking. Yesiller et al. (2000) and Tang et al. (2008) have observed that cracks appeared at the same locations as the first drying cycle in the second and third cycles $[6,17]$. However, this observation was not evident in present research after comparing Fig. 7 with Fig. 3. After the second drying path, the shapes of clods were more irregular and the cracks were much coarser (Fig. 7). Most interestingly, the clods were degraded significantly. The wetting-drying cycles caused dramatic aggregate formation from initially non-aggregated soil. The clod surface is also not smooth any more.

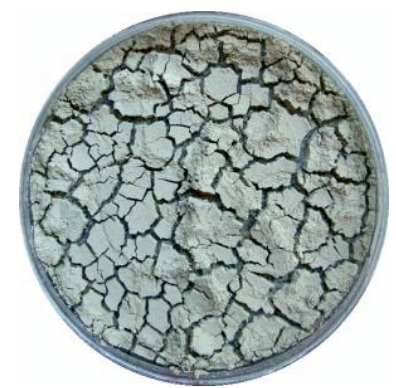

Figure 7. The crack pattern after the second wetting-drying cycle.

\subsection{Subsequent wetting-drying cycles}

Typical image of specimen during the third wetting path is presented in Fig. 8. The observations are different from that during the second wetting path (Fig. 6). After water were put into glass cup, clods degraded rapidly. Only about 1 min later, the original cracks were completely disappeared, and no new microcracks were observed. This is because the stability of clod during the third wetting path was mainly controlled by the bonding strength between the formed aggregates in the second wetting-drying cycle. As the image shown in Fig. 8, the specimen is composed of large amount of individual aggregates. It is proved that the degradations of clods in the third wetting path are the results of breakdown of the bonds between aggregates. During the fourth and fifth wetting path, no significant difference was observed with the third wetting path, and no image is presented.

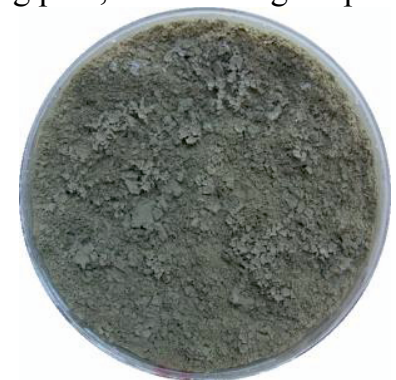

Figure 8. The typical crack pattern during the third wetting path (after about 1 min wetting).

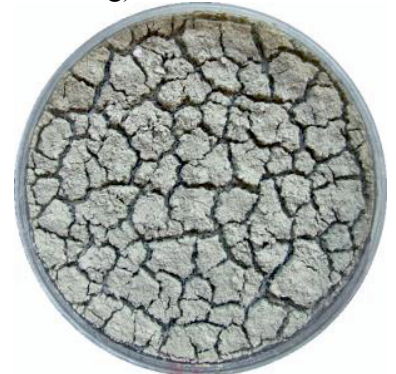

(a) After the third wetting-drying cycle 


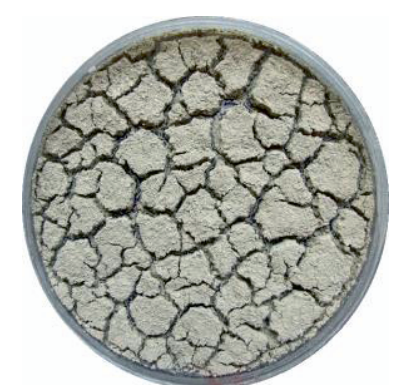

(b) After the fourth wetting-drying cycle

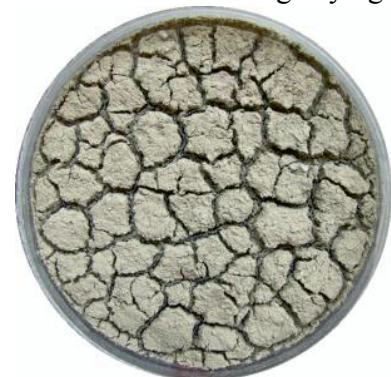

(c) After the fifth wetting-drying cycle

Figure 9. Crack patterns after the third, fourth and fifth wettingdrying cycle.

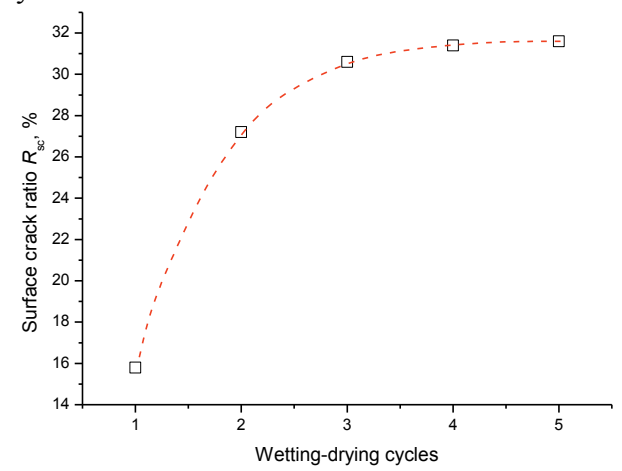

(a) Surface crack ratio

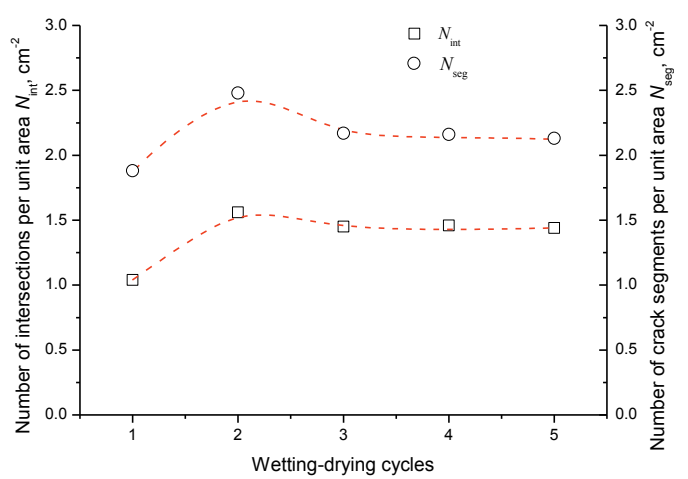

(b) Number of intersections and crack segments per unit area

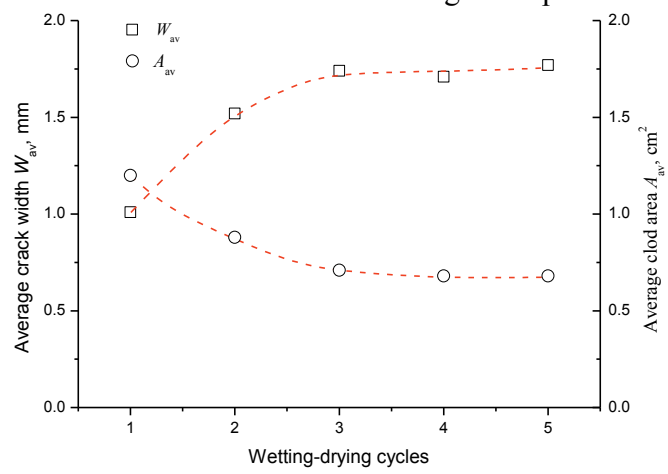

(c) Average crack area and clod area

Figure 10. Variation crack quantitative parameters with the number of wetting-drying cycles.
The final crack patterns for the last three wetting-drying cycles are shown in Fig. 9. They show similar morphology characteristics, but they are different from the crack pattern obtained from the first wetting-drying cycle (Fig. 3). Fig. 10 present the variation of some crack quantitative parameters with the number of wettingdrying cycles, including surface crack ratio $R_{\text {sc }}$, number of intersections per unit area $N_{\text {int }}$, number of crack segments per unit area $N_{\text {seg }}$, average crack width $W_{\text {av }}$ and clod area $A_{\text {av }}$. Before the third wetting-drying cycle was reached, it can be seen that an increase in number of wetting-drying cycles was accompanied by increase in $R_{\mathrm{sc}}$ and $W_{\text {av }}$. For $N_{\text {int }}$ and $N_{\text {seg }}$, they reached the peak values after the second cycle. However, $A_{\text {av }}$ generally decreases with increasing number of wetting-drying cycles. After the third wetting-drying cycle, these crack quantitative parameters almost keep constant, and the effect of increasing cycles is insignificant. Based on the quantification results of the crack patterns, it can be concluded that the soil cracking behaviour reached equilibrium state after the soil underwent three wettingdrying cycles. The soil properties will not be significantly influenced by the subsequent cycles.

\subsection{Effect of wetting-drying cycles on structure}

By comparing the final crack patterns shown in Figs. 3, 7 and 9 , it can be found that the wetting-drying cycles can significantly change soil structure and give rise to intensification of material heterogeneity. In the first wetting-drying cycle, the specimen was subjected to drying from relative homogenous slurry state. The final clods are dense and the surfaces are smooth (Fig. 3). However, after the second and third cycles, the apparent homogenous slurry structure was completely replaced with aggregated structure (Figs. 7 and 9). A strong increase in the inter-aggregate porosity can be observed after sequences of wetting-drying cycles. These aggregates and the corresponding macro-pores were mostly generated during the second wetting path, and they were maintained during the subsequent drying paths.

The laboratory test results obtained in the present work can be probable used to highlight the natural regeneration of soil. Actually, in the agricultural soil mechanics point of view, mechanical impacts of agricultural machineries and grazing animals can induce excessive soil compaction; that alters the structure of cultivated soil and thus changes a number of key soil properties for crop production and the environment, and results in degradation of soil physical qualities [18]. To regenerate the deteriorated soil has emerged as a major issue. Recently, McHugh et al. (2009) assessed changes in soil properties over a 22 month period on a site which had been used for crop and pasture production for 100 years under conventional tillage practices [19]. It was found that the cropping zone bulk density decreases of $0.23 \%$ per month in the zone isolated from wheel traffic and soil tillage. However, due to the consideration of the 
environmental factors and energy consumption, soil in compacted zones is expected or even encouraged to regenerate naturally (through natural climatic conditions) other than through the traditional deep tillage. After Drewry (2006), the mechanisms of natural regeneration of soil are: soil shrinkage and swelling, cracking or micro-cracking from rapid wetting to reduce soil tensile strength, the wetting and drying process, freezing and thawing, frost penetration, plant root penetration, earthworm burrowing [20]. The results in the present work can be then useful when studying the soil regeneration by wetting/drying process and by cracking. In general, under unconfined conditions, wetting-drying cycles can give rise to a decrease in soil bulk density and an increase in crack extend and also aggregation, as the obtained results presented in the above sections. The soil permeability, macro-pore space and continuity may therefore be enhanced, so as to improve soil aeration and rapid drainage of water and solutes through soil.

\section{Conclusions}

Desiccation cracking behavior of soil subjected to five wetting-drying cycles was investigated. The effect of wetting-drying cycles on the morphology characteristics of crack pattern were quantitatively analyzed and discussed.

During the first wetting-drying cycle, it was found that cracking water content $w_{\mathrm{c}}$ at the onset of surface cracking is close to the plastic limit of the tested soil. The extent of surface cracking was quantified with surface crack ratio $R_{\mathrm{sc}}$, which increased with decreasing water content and reached stabilization around shrinkage limit.

The subsequent wetting-drying cycles especially the second cycle leaded to significant rearrangement of soil particles and modification of pore system. In most of the cases, these structure changes were not reversible. During the second wetting path, rapid clods slaking phenomenon was observed due to softening of particle bonds, developed differential swelling pressure and entrapment of pore air. The original cracks were closed or healed immediately and large amount of new microcracks were appeared on soil surface, which divided the clods into several aggregates. A typical aggregated structure was constructed after the second wetting path and significantly enhanced soil heterogeneity.

Wetting and drying of soil with an increasing number of cycles have been shown to reach an equilibrium state, where the soil system nearly behaves in a reversible manner. For the tested soil, before the third wettingdrying cycle was reached, the surface crack ratio and the average crack width increased while the average clod area decreased with increasing the number of wettingdrying cycles. The number of intersections and crack segments per unit area reached the peak values after the second wetting-drying cycle. After the third wettingdrying cycle was reached, the effect of increasing wetting-drying cycles on crack patterns is insignificant. It indicated that the third cycle seems to be the transition point where the structure changes resulted from the subsequent cycles were generally reversible.

\section{Acknowledgements}

This work was gratefully supported by the National Natural Science Foundation of China for Excellent Young Scholars (Grant No. 41322019), National Natural Science Foundation of China (Grant No. 41572246), Key Project of National Natural Science Foundation of China (Grant No. 41230636), and the Fundamental Research Funds for the Central Universities. The authors also wish to acknowledge the support of the European Commission via the Marie Curie IRSES project GREAT Geotechnical and geological Responses to climate change: Exchanging Approaches and Technologies on a world-wide scale (FP7-PEOPLE-2013-IRSES- 612665).

\section{References}

1. P.H. Morris, J. Graham, D.J. Williams, Can. Geotech. J. 29, 15 (1992)

2. V.Y.Chertkov, Soil Sci. Soc. Am. J. 64, 4 (2000)

3. B. A.Albrecht, C.H. Benson, J. Geotech. Geoenviron. 27, 9 (2001)

4. C.J. Miller, H. Mi, N. Yesiller, J. Am. Water Resour. As. 34, 10 (1998)

5. H. Nahlawi, J. Kodikara. Geotech. Geol. Eng. 24, 24 (2006)

6. C.S. Tang, B. Shi, C. Liu, et al., Eng. Geo. 101, 14(2008)

7. C.S. Tang et al., Eng. Geo. 114, 6 (2010a)

8. C.S. Tang et al., J. Mater. Civil Eng. 23, 6 (2010b)

9. C.S. Tang et al., Appl. Clay Sci. 52, 9 (2011)

10. A.N. Abu-Hejleh, D. Znidarčić, J. Geotech. Eng. 121, 10 (1995)

11. H. Péron, J.Y. Delenne, L. Laloui, M.S. EI Youssoufi, Comput. Geotech. 36, 9 (2009)

12. A. Corte, A. Higashi. Wilmette, Illinois. (1960)

13. C.S. Tang, B. Shi, C. Liu, et al., Chinese J. Geotech. Eng. 27, 6 (2007)

14. R. Rodríguez, M. Sánchez, A. Ldesma, A. Lioret, Can. Geotech. J. 44, 15 (2007)

15. S.M. Rao, B.V.V. Reddy, M. Muttharam. Eng. Geo. 60, 11 (2001)

16. R.N Yong, B.P. Warkentin, Elsevier, Amsterdam, (1975)

17. N. Yesiller, C.J. Miller, G. Inci, K.Yaldo, Eng. Geo. 57, 17 (2000)

18. K.Y.Chan, A.Oates, A.D. Swan, et al, Soil Till. Res., 89, 9 (2006)

19. A.D. McHugh, J.N Tullberg, D.M. Freebairn, Soil Till. Res. 104, 9 (2009)

20. J. J. Drewry, Agr. Ecosys. Environ. 114,11 (2006) 